\title{
Citizen's Response to a State's Environmental Management through Enforcement of Ban
}

\author{
V. Darling Selvi, G. Ilankumaran
}

\begin{abstract}
Single use plastic bags have been banned by many countries, states and cities globally in an attempt to curb the massive impact of plastics on the environment. Plastic bag litter can clog drainage systems and result in those systems failing and flooding breaking out, which can result in damage. This litter is also a serious threat to animals and their habitats. Tamil Nadu, on January 1, 2019, became the fourth state in India to implement a ban on single-use plastics. Maharashtra was the first do it on March 23, 2018, Telangana followed the feat in June and Himachal Pradesh in July. This paper tries to bring the opinion of 150 sample respondents from Tirunelveli District on the awareness and response of Plastic usage and avoidance. The researcher used Trend analysis, $t$ test, means, ANOVA, Rotated Factor Analysis, transformation matrix and Confirmatory Factor Analysis after the completion of suitable reliability test. This study brings to light the steps taken by the Government of Tamilnadu to reduce the usage of plastics and the opinion of the sample respondents regarding the ban of plastics. The study reveals that there is considerable improvement in the steps taken in the reduction of plastics in different zones. The opinion of the sample respondents in respect to the ban of plastics is highly significant in different dimensions such as personal, awareness, environmental and the availability of substitutes. The model framed is fit as per confirmatory factor analysis. Hence it is concluded that wider spread of awareness on environmental protection along with the introduction of proper substitutes for the plastics will wipe away the usage of plastics among the public and thereby the environment will be protected for a better tomorrow.
\end{abstract}

Keywords : Awareness, Ban, Environment, Model, Opinion, Plastics.

\section{INTRODUCTION}

Single use plastic bags have been banned by many countries, states and cities globally in an attempt to curb the massive impact of plastics on the environment. Single-use plastic bags, also known as low-density polyethylene (LDPE) bags, have become a scapegoat for the massive problem of plastic pollution. Plastic bag litter can clog drainage systems and result in those systems failing and flooding breaking out, which can result in damage. This litter is also a serious threat to animals and their habitats. Efforts to voluntarily reduce plastic bags and recycle bags have proven ineffective. Plastic

Revised Manuscript Received on July 22, 2019.

Dr. V. Darling Selvi , Assistant Professor of Commerce, Rani Anna Government College for Women, Tirunelveli -8, Tamilnadu

Dr. G. Ilankumaran, Associate Professor, Alagappa Institute of Management, Alagappa University, Karaikudi, Tamilnadu bags must be banned in order to reduce pollution. Plastic bags cause land, air as well as water pollution. This is the reason why these have been banned in various countries. However, these are still being widely used in most parts of the world and are proving to be hazardous for the environment. One of the biggest threats about plastic bags is that they threaten the environment. Plastic bags pollute the land and water, since they are lightweight, plastic materials can travel long distances by wind and water. Besides, these material bags are made from non-renewable resources. The majority of plastic bags is made of polypropylene, a material derived from petroleum and natural gas. Both of them are non-renewable fossil fuel-based resources, which contribute to global climate change. Most of the plastics are not recyclable. Though some kinds of plastic bags can be recyclable, many done possess the technology or the plants to recycle them. According to various estimates, the actual recycling rate for plastic bags is about 56 percent. Since plastic bags are not recyclable, they end up in the oceans. While they reach, they break up into tiny little pieces and are consumed by wildlife. It is estimated that 46,000-1,000,000 plastic fragments floating within every square mile of the world's oceans. Due to their size, they are often mistaken for food by animals, birds, and marine life like fish, whales and sea turtles. Toxic chemicals from plastic bags can damage the blood and tissues. Frequent exposures can lead to cancers, birth defects, impaired immunity, hormone changes, endocrine disruption and other serious ailments. This paper tries to bring the opinion of the people of Tirunelveli District on the awareness and response of Plastic usage and avoidance. Experts have estimated that annual waste generation in India will increase to 165 million tonnes by 2030. This means that around 66,000 hectares of land is needed to set up a landfill site which is 10 metres high and can hold up to 20 years' waste. That is almost $90 \%$ of Bengaluru's area. If we do not change our waste practices now then we will soon be buried in our own muck

- Plastics take around 500 to 1000 years to degrade

- India is generating 56 lakh tonnes of plastic waste annually 
- India's contribution to plastic dump into the world's ocean is $60 \%$.

\section{Reviews and Gap on Plastic Ban}

Turner and Sutton (2012) in their articles reported that plastic bags is a growing problem and can be seen in many different forms. The first part of our project will focus on the various areas affected by the growing use and waste of plastic bags: oceans, streams, landfills, air and natural resources. In developed societies, plastic bags are discarded in landfills where they take up a significant portion of landfill space. Not only is space an issue, but it takes hundreds of years for plastic bags to completely decompose

Unnikrishnan (2012) in his "A Study on Customer Awareness of Green Marketing and Green Brand Effectiveness" has examined the factors such as customer awareness of green brands, customer perception regarding Price, availability, greenness and effectiveness. Attitudes are changing toward the environment to encourage innovation for conservation.

Park (2013) in his article mentioned that plastic takes up large part of society, from plastics used for furniture, electronics, to small households needs like containers and grocery bags. Since plastic first became available to consumers, it became widely used, due to the advantages it provides, such as lightweight, durability and its ability to mold into any products with chemicals and additives. However, there are also a number of disadvantages that plastic poses, including health problems starting from manufacturing to consumption and negative environmental impacts created by accumulation of plastic wastes. Today, the management of plastic wastes has become one of the most challenging problems in our society. It seems even serious if we think about the future generation that has to deal with continuously growing amount of plastic wastes accumulated in the environment.

The reviews reviewed the growing use and waste of plastic bags, talked about the evils of plastic usage, Customer Awareness of Green Marketing and Green Brand Effectiveness and evaluated the merits and demerits of the usage of plastics, reminded the management of plastic wastes has become one of the most challenging problems in our society and worried about the future generation that has to deal with continuously growing amount of plastic wastes accumulated in the environment while this study deals with the steps taken by the government in the eradication of plastic waste and the opinion of the general public in adapting the avoidance of plastic items.

\section{Plastic Ban in Tamilnadu}

Plastic has been completely banned in all other 17 states and UTs except the following 11 states where it had been partially banned in August, 2017: Andhra Pradesh, Arunachal Pradesh, Assam, Goa, Gujarat, Karnataka, Odisha, Tamil Nadu, West Bengal, Uttar Pradesh and Uttarakhand. Tamil Nadu, on January 1, 2019, became the fourth state in India to implement a ban on single-use plastics. Maharashtra was the first do it on March 23, 2018, Telangana followed the feat in June and Himachal Pradesh in July. But most Indian states, or almost all, have banned plastic bags. Single-use plastics are disposable plastic items that are commonly used for packaging and include items intended to be used only once before they are thrown away or recycled. When the Tamil Nadu government banned single-use plastic from January 1, 2019, the hotel industry in the state went into a tizzy as they were still scrambling for alternatives. To allay the fears, the Tamil Nadu Pollution Control Board (TNPCB) issued a fresh advisory on January 1, 2019, to all the concerned industries asking them to certain measures to comply with the ban. It asked all industries to put up a display board made of metal (not in PVC Flex) with pictorial representation of the banned one-time use and throwaway plastic items at the entrance of the industry to inform visitors about the implementation of the ban. It also suggested that they declare their premise as "plastic-free zone" and stick prominent stickers for it.

The Tamil Nadu government's notification, however, provides for a few exemptions, including use of plastic bags for export in Special Economic Zones, plastic bags and sheets used in forestry and horticulture nurseries, plastic bags/sheets used to pack dairy products and carry bags bearing a label 'compostable'. This ban was implemented after plastic waste began causing blockage of sewers and drains apart from resulting into pollution of water bodies. The ban primarily covers the use of plastic carry bags, plastic plates, plastic cups, plastic flags, small plastic sachets used in packaging water, among others. Exclusions, however, apply for milk, curd, oil, and medicine packaging. The Tamil Nadu Pollution Control Board (TNPCB) has listed 14 plastic products to be banned, including plates, cups, bags, plastic packaging material, plastic-coated items, non-woven bags, straws and plastic sheets. Items excluded are plastic cases containing milk, curd, biodegradable plastics and packaging plastics like water bottle from big firms by the government and others. The government has identified a list of 12 eco-friendly alternatives, including cloth bags, glass containers, paper plates and cups, and banana leaves. Retail outlets have already started putting up notices asking people to bring cloth bags.

\section{Banned items}

- Food processing and packing plastic used in hotels

- Plastic sheets used for table mats and tablecloths.

- Thermocol plates used for serving food.

- Plastic coated paper plates.

- Plastic bags used for gifting during special occasions.

- Plastic coated tumblers used in state0run liquor shops, small vendors, serving

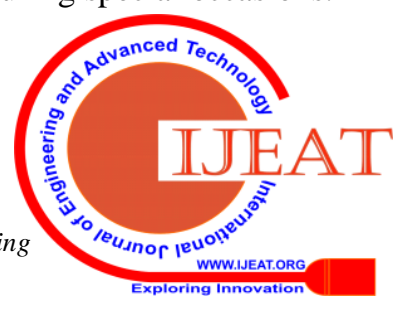


coffee, tea, water on occasions.

- One-time usable plastic coffee and tea cups used in shops and homes.

- Normal plastic made tumblers in commercial use.

- Thermocol tumblers and cups.

- Plastic coated paper bags which are used in shops for packing products for the buyers.

- Water packets selling by small vendors around Tamil Nadu.

- Plastic straws used for serving cold drinks, milkshakes in shops, theatres and hotels.

- Plastic carry bags used for everyday usage by people.

- Plastic printed flags in sale in shops.

\section{EFFects of Plastic Ban}

Economic Effects: Business sales and profits are negatively affected by plastic bag bans. Plastic bag bans not only provide an unfair advantage to retailers in a geographic area without a plastic bag ban, they also have additional unintended consequences. The theft of store shopping carts and shopping baskets is higher in areas with plastic bag bans. Additionally, customers use more plastic produce bags, which undercut the effect of the ban. Overall, plastic bag bans increase prices for consumers, decrease profit for producers, and decrease economic activity in the area affected by the plastic bag ban.

Employment Effects: Banning plastic bags reduces retail employment. According to a survey on the economic effects of the plastic bag ban in Los Angeles County, stores that were inside the ban area reduced their employment by more than $10 \%$ while stores outside the ban area increased their employment by $2.4 \%$. Retail jobs are not the only jobs that would be affected if a plastic bag ban were implemented. A large portion of plastic bags are made in the United States, and the plastics manufacturing industry employs more than 30,000 people whose jobs would be at stake if plastic bag bans became widespread.

Environmental Effects: While the economic and employment effects of plastic bag bans are substantial, there are no environmental benefits to banning plastic bags. Plastic bags require less energy to produce and recycle, and they create less municipal waste than cloth bags. Cloth bags need to be used 104 times before they have an environmental advantage over plastic bags, and most cloth bags are used half that amount. Reusing cloth bags also has potential negative health effects as this practice can lead to cross-contamination and disease.

Table- I: Plastic Pollution Free Tamil Nadu Campaign (MT)

\begin{tabular}{|c|c|c|c|c|c|c|}
\hline Zones & $\mathbf{3 0 . 1 2 . 2 0 1 8}$ & $\mathbf{0 1 . 0 1 . 2 0 1 9}$ & $\mathbf{0 2 . 0 1 . 2 0 1 9}$ & $\mathbf{0 3 . 0 1 . 2 0 1 9}$ & $\mathbf{0 4 . 0 1 . 2 0 1 9}$ & Total \\
\hline $\mathrm{Z} 1$ & 36 & 0 & 39.01 & 149.7 & 1159 & $\mathbf{0 . 2 2}$ \\
\hline $\mathrm{Z} 2$ & 97 & 43 & 315 & 48 & 195 & $\mathbf{0 . 5 0}$ \\
\hline $\mathrm{Z} 3$ & 45 & 59 & 56.2 & 81.5 & 86.1 & $\mathbf{0 . 2 4}$ \\
\hline $\mathrm{Z} 4$ & 0 & 0 & 720 & 823.5 & 794 & $\mathbf{1 . 5 4}$ \\
\hline $\mathrm{Z} 5$ & 0 & 0 & 528 & 505.5 & 1126 & $\mathbf{1 . 0 3}$ \\
\hline $\mathrm{Z} 6$ & 0 & 0 & 500 & 3240 & 2698 & $\mathbf{3 . 2 0}$ \\
\hline $\mathrm{Z} 7$ & 65 & 563 & 664 & 319 & 374 & $\mathbf{1 . 6 7}$ \\
\hline $\mathrm{Z} 8$ & 485 & 439 & 761 & 373 & 373 & $\mathbf{2 . 0 6}$ \\
\hline $\mathrm{Z} 9$ & 580 & 0 & 362 & 593 & 527 & $\mathbf{1 . 4 7}$ \\
\hline $\mathrm{Z} 10$ & 186 & 158 & 859 & 378 & 656 & $\mathbf{1 . 8 6}$ \\
\hline $\mathrm{Z} 11$ & 75 & 71 & 2376 & 174 & 128 & $\mathbf{2 . 7 0}$ \\
\hline $\mathrm{Z} 12$ & 43 & 52 & 135 & 1369 & 140 & $\mathbf{1 . 6 0}$ \\
\hline $\mathrm{Z} 13$ & 168 & 156 & 156 & 151 & 52 & $\mathbf{0 . 6 3}$ \\
\hline $\mathrm{Z} 14$ & 67 & 47 & 218.5 & 389 & 186.5 & $\mathbf{0 . 7 2}$ \\
\hline Z15 & 36 & 662 & 622 & 593.65 & 343.1 & $\mathbf{1 . 9 1}$ \\
\hline Total & $\mathbf{1 . 8 8}$ & $\mathbf{2 . 2 5}$ & $\mathbf{8 . 3 1}$ & $\mathbf{9 . 1 9}$ & $\mathbf{8 . 8 4}$ & $\mathbf{3 0 . 4 7}$ \\
\hline Trend \% & $\mathbf{1 0 0}$ & $\mathbf{1 2 0}$ & $\mathbf{4 4 2}$ & $\mathbf{4 8 9}$ & $\mathbf{4 7 0}$ & \\
\hline
\end{tabular}

In Tamilnadu, Plastic Pollution Free Campaign has been conducted in various zones in different stages. As per the records, it is known that the eradication of plastics took place in an up scaling manner recording a growth rate of 20 percent in the second campaign, 342 percent in the third campaign, 389 percent in the fourth campaign and 370 percent in the fifth campaign by considering the first campaign as the base one that is 100 .

\section{Opinion on Plastic Ban}

An opinion survey has been conducted among 150 sample respondents in Tirunelveli District regarding the plastic ban is narrated with the following result in the table below. A total of 18 statements have been taken for gathering opinion and for further analysis. 
Table 2 Test of Reliability for the Opinion on the Plastic Ban

\begin{tabular}{|c|c|c|c|c|}
\hline \multicolumn{5}{|c|}{ Item-Total Statistics } \\
\hline Statements & $\begin{array}{l}\text { Scale Mean if } \\
\text { Item Deleted }\end{array}$ & $\begin{array}{l}\text { Scale Variance } \\
\text { if Item Deleted }\end{array}$ & $\begin{array}{l}\text { Corrected } \\
\text { Item-Total } \\
\text { Correlation }\end{array}$ & $\begin{array}{l}\text { Cronbach's } \\
\text { Alpha if Item } \\
\text { Deleted }\end{array}$ \\
\hline Non availability of plastic equivalent packaging & 58.94 & 94.826 & .418 & .816 \\
\hline Hard to adapt the system of banning & 59.19 & 94.021 & .463 & .814 \\
\hline Green packaging is costly & 59.24 & 94.484 & .410 & .816 \\
\hline Force to carry the bag & 59.22 & 91.494 & .536 & .809 \\
\hline Awareness on green packaging is poor & 59.21 & 94.041 & .425 & .816 \\
\hline Willingness to know about green packaging & 59.27 & 93.681 & .450 & .814 \\
\hline Buying green packaging by force & 59.25 & 93.404 & .445 & .815 \\
\hline Helpful to the society & 59.24 & 94.146 & .397 & .817 \\
\hline Protects the environment & 59.16 & 94.030 & .400 & .817 \\
\hline Difficult to dispose properly & 59.47 & 93.534 & .425 & .816 \\
\hline Unaware about alternative packaging & 59.51 & 93.941 & .394 & .817 \\
\hline $\begin{array}{l}\text { Eco-friendly packaging does not bring any } \\
\text { benefit }\end{array}$ & 59.54 & 93.944 & .394 & .817 \\
\hline $\begin{array}{l}\text { Government has not provided cheap and } \\
\text { convenient alternatives to people }\end{array}$ & 59.44 & 94.917 & .367 & .819 \\
\hline No immediate solutions to replace & 59.43 & 93.484 & .419 & .816 \\
\hline The alternatives are yet to evolve & 59.36 & 94.201 & .433 & .815 \\
\hline Feel shy of carry cloth bags & 59.36 & 94.763 & .368 & .819 \\
\hline $\begin{array}{l}\text { It is the duty of the manufacturer to provide } \\
\text { goods with bio-degradable packages }\end{array}$ & 59.26 & 95.565 & .319 & .822 \\
\hline $\begin{array}{l}\text { Thinking that environment safety is the } \\
\text { responsibility of the government }\end{array}$ & 58.97 & 96.111 & .365 & .819 \\
\hline \multicolumn{5}{|c|}{ Reliability Statistics } \\
\hline Cronbach's Alpha & .825 & $\mathrm{~N}$ of Items & 18 & \\
\hline
\end{tabular}

Test of reliability is conducted through Cronbach's Alpha and the value derived under this test is .825 which is sufficient for further testing and so all the 18 statements were taken for further analysis.

Table 3 ANOVA test for the Opinion on the Plastic Ban

\begin{tabular}{|l|l|c|c|c|c|c|}
\hline \multicolumn{2}{|c|}{ Items } & Sum of Squares & df & Mean Square & F & Sig \\
\hline \multirow{2}{*}{ Between People } & Between Items & 2286.698 & 394 & 5.804 & & \\
\multirow{3}{*}{ Within People } & Residual & 682.598 & 11.013 & 6.741 & \multirow{3}{*}{10.563} & \multirow{2}{*}{.000} \\
\cline { 2 - 6 } & Total & 6993.611 & 6715 & 1.041 & & \\
\hline \multicolumn{2}{|l|}{ Total } & 9280.310 & 7109 & 1.305 & & \\
\hline \multicolumn{2}{|l|}{ Grand Mean = 3.49 }
\end{tabular}

The ANOVA test reveals that the statements are statistically significant with the $\mathrm{p}$ value of .000 with the $\mathrm{F}$ (394, 17): 10.563. The grand mean is 3.49 . This test further helps to prove the reliability of the statements of analysis.

Table 4 One-Sample Test for the Opinion on the Plastic Ban

\begin{tabular}{|c|c|c|c|c|c|}
\hline Statements & & $t$ & $\begin{array}{c}\text { Sig. } \\
(2-t a i l e d \\
)\end{array}$ & Mean & $\begin{array}{c}\text { 95\% Confidence } \\
\text { Interval of the } \\
\text { Difference }\end{array}$ \\
\cline { 3 - 6 } & & & Lower & Upper \\
\hline
\end{tabular}




\begin{tabular}{|l|c|c|c|c|c|} 
Thinking that environment safety is the responsibility of & & & & \\
the government & 73.82 & .000 & 3.80 & 3.7 & 3.9 \\
\hline Non availability of plastic equivalent packaging & 72.57 & .000 & 3.83 & 3.73 & 3.93 \\
\hline Hard to adapt the system of banning & 68.24 & .000 & 3.58 & 3.48 & 3.68 \\
\hline Green packaging is costly & 63.69 & .000 & 3.52 & 3.42 & 3.63 \\
\hline Awareness on green packaging is poor & 63.37 & .000 & 3.55 & 3.44 & 3.66 \\
\hline Willingness to know about green packaging & 63.12 & .000 & 3.49 & 3.38 & 3.6 \\
\hline The alternatives are yet to evolve & 62.55 & .000 & 3.41 & 3.3 & 3.51 \\
\hline Force to carry the bag & 61.95 & .000 & 3.55 & 3.44 & 3.66 \\
\hline Buying green packaging by force & 61.60 & .000 & 3.52 & 3.41 & 3.63 \\
\hline Protects the environment & 61.29 & .000 & 3.61 & 3.49 & 3.72 \\
\hline Helpful to the society & 60.22 & .000 & 3.53 & 3.41 & 3.64 \\
\hline $\begin{array}{l}\text { It is the duty of the manufacturer to provide goods with } \\
\text { bio-degradable packages }\end{array}$ & 58.17 & .000 & 3.50 & 3.39 & 3.62 \\
\hline Feel shy of carry cloth bags & 58.13 & .000 & 3.41 & 3.29 & 3.53 \\
\hline $\begin{array}{l}\text { Government has not provided cheap and convenient } \\
\text { alternatives to people }\end{array}$ & 57.55 & .000 & 3.33 & 3.22 & 3.45 \\
\hline Difficult to dispose properly & 56.30 & .000 & 3.30 & 3.19 & 3.42 \\
\hline No immediate solutions to replace & 56.17 & .000 & 3.34 & 3.22 & 3.46 \\
\hline Unaware about alternative packaging & 54.35 & .000 & 3.26 & 3.14 & 3.38 \\
\hline Eco-friendly packaging does not bring any benefit & 53.82 & .000 & 3.23 & 3.11 & 3.34 \\
\hline
\end{tabular}

As per $\mathrm{t}$ test, it is noted that the statements "Thinking that environment safety is the responsibility of the government" has the highest score of 73.82 which is followed by the statements Non availability of plastic equivalent packaging (t:72.57, p:.000), Hard to adapt the system of banning (t:68.24,p:.000), Green packaging is costly (t:63.69, p:.000), Awareness on green packaging is poor ( $\mathrm{t}: 63.37, \mathrm{p}: .000)$, Willingness to know about green packaging (t:63.12, p:.000), The alternatives are yet to evolve (t:62.55,p:.000), Force to carry the bag (t:61.95, p:.000), Buying green packaging by force (t:61.95,p:.000), Buying green packaging by force (t:61.60,p:.000), Protects the environment (t:61.29,p:.000), Helpful to the society (t:60.22, p:.000), It is the duty of the manufacturer to provide goods with bio-degradable packages (t:58.17,p:.000), Feel shy of carry cloth bags (t:58.13,p:.000), Government has not provided cheap and convenient alternatives to people (t:57.55,p:.000), Difficult to dispose properly (t:56.30,p:.000), No immediate solutions to replace (t:56.17,p:.000), Unaware about alternative packaging (t:54.35,p:.000) and Eco-friendly packaging does not bring any benefit (t:53.82,p:.000). The mean is high for the statement Non availability of plastic equivalent packaging (3.83) and is low for Eco-friendly packaging does not bring any benefit (3.23). All the statements are statistically significant as all the $p$ values are 0.000 which is below the stipulated value of 0.05 .

Table 5 Factor Analysis for Opinion on the Plastic Ban

\begin{tabular}{|l|l|l|l|l|}
\hline \multirow{2}{*}{ Statements } & \multicolumn{4}{|c|}{ Components } \\
\cline { 2 - 6 } & $\begin{array}{l}\text { Persona } \\
\mathbf{l}\end{array}$ & $\begin{array}{l}\text { Awarenes } \\
\mathbf{s}\end{array}$ & Environmental & Substitutes \\
\hline Feel shy of carry cloth bags & $\mathbf{. 6 3 9}$ & -.225 & .060 & .444 \\
\hline
\end{tabular}


Citizen's Response to a State's Environmental Management through Enforcement of Ban

\begin{tabular}{|c|c|c|c|c|}
\hline Hard to adapt the system of banning & .620 & 231 & .129 & .053 \\
\hline Non availability of plastic equivalent packaging & .595 & 137 & .312 & -.145 \\
\hline No immediate solutions to replace & .547 & .232 & .033 & .160 \\
\hline Unaware about alternative packaging & .529 & .178 & .168 & .019 \\
\hline Willingness to know about green packaging & .326 & .326 & .184 & .250 \\
\hline Awareness on green packaging is poor & .088 & .657 & .199 & .066 \\
\hline $\begin{array}{l}\text { Government has not provided cheap and convenient } \\
\text { alternatives to people }\end{array}$ & .086 & .636 & -.212 & .456 \\
\hline Force to carry the bag & .310 & .544 & .163 & .228 \\
\hline Green packaging is costly & .162 & .533 & .408 & -.179 \\
\hline Eco-friendly packaging does not bring any benefit & .321 & .484 & .090 & .011 \\
\hline Protects the environment & .184 & -.030 & .646 & .202 \\
\hline Difficult to dispose properly & .222 & .114 & .610 & .064 \\
\hline Helpful to the society & -.089 & .249 & .588 & .282 \\
\hline Buying green packaging by force & .232 & 184 & .554 & .074 \\
\hline $\begin{array}{l}\text { It is the duty of the manufacturer to provide goods } \\
\text { with bio-degradable packages }\end{array}$ & -.025 & .148 & .101 & .724 \\
\hline $\begin{array}{l}\text { Thinking that environment safety is the } \\
\text { responsibility of the government }\end{array}$ & .106 & -.043 & .342 & .594 \\
\hline The alternatives are yet to evolve & .243 & .261 & .143 & .434 \\
\hline$\%$ of Variance & 13.78 & 11.50 & 11.06 & 10.69 \\
\hline Cumulative \% & 13.78 & 25.28 & 36.34 & 47.03 \\
\hline$\%$ to total & 29 & 24 & 24 & 23 \\
\hline
\end{tabular}

Personal Hindrances: Generally it is the personal likes and dislikes, preferences and hindrances affect the usage or denial of particular products. Here six statements are filtered under this head such as Feel shy of carry cloth bags (.639), Hard to adapt the system of banning (.620), Non availability of plastic equivalent packaging (.595), No immediate solutions to replace (.547), Unaware about alternative packaging (.529) and Willingness to know about green packaging (.326). The variance of this factor is 13.78 percent which constitutes 29 percent out of total. Lack of Awareness: Awareness building is the basic criteria in every business or profession which has no exception in case of plastic banning too. This factor consists of five statements such as Awareness on green packaging is poor (.657), Government has not provided cheap and convenient alternatives to people (.636), Force to carry the bag (.544), Green packaging is costly (.533) and Eco-friendly packaging does not bring any benefit
(.484). The variance of this factor is 11.50 percent which constitutes 24 percent out of total.

Environmental Effect: Protection of environment is the basic idea behind the banning of plastics. This factor includes four statements such as Protects the environment (.646), Difficult to dispose properly (.610), Helpful to the society (.588) and buying green packaging by force (.554). The variance of this factor is 11.06 percent which constitutes 24 percent out of total.

Non availability of Substitutes: People always search for alternatives when there is a hurdle. The statements filtered in this factor are three such as It is the duty of the manufacturer to provide goods with bio-degradable packages (.724), Thinking that environment safety is the responsibility of the government (.594) and The alternatives are yet to evolve (.434). The variance of this factor is 10.69 percent which constitutes 23 percent out of total.

Table 6 Component Transformation Matrix Component Transformation Matrix

\begin{tabular}{|l|c|c|c|c|}
\hline \multicolumn{5}{|c|}{ Component Transformation Matrix } \\
\hline \multicolumn{1}{|c|}{ Components } & Personal & Awareness & Environmental & Substitutes \\
\hline Personal & .573 & .523 & .501 & .383 \\
\hline Awareness & -.356 & -.128 & -.157 & .912 \\
\hline Environmental & .141 & -.777 & .611 & .051 \\
\hline Substitutes & .725 & -.325 & -.592 & .136 \\
\hline $\begin{array}{l}\text { Extraction Method: Principal Component Analysis. } \\
\text { Rotation Method: Varimax with Kaiser Normalization. }\end{array}$ \\
\hline
\end{tabular}

\section{Source: Derived}

From the Component Transformation Matrix, it is apparent that the factor Personal has positive relationship with Awareness (.573), Environmental (.501) and Substitutes (.383), the factor Awareness has high and positive relationship with Substitutes (.912), the factor Environmental has high and 
negative relationship with Awareness (-.777) and Substitutes has positive relationship with Personal (.725). Hence it is observed that personal awareness of substitutes leads to a successful banning of plastics as far as the sample group is concerned. Based on the factor analysis a structural equation modeling is developed and is presented with fitness model as below.

\section{Confirmatory Factor Analysis}

Based on the factors derived from the factor analysis, an attempt has been made to evaluate the opinion on Plastic ban with the help of Confirmatory Factor Analysis.
There are four factors derived such as Personal, Awareness, Environmental and Substitutes. The figure and the confirmatory test are given below.

Table 7 Results of Goodness of Fit Test for Confirmatory Factor Analysis

\begin{tabular}{|l|c|c|c|c|c|}
\hline \multicolumn{1}{|c|}{ Model } & $\begin{array}{c}\text { Normed Chi-square } \\
\left(x^{2} / \mathrm{df}\right)\end{array}$ & P-Value & CFI & NFI & RMESA \\
\hline Study model & 2.385 & 0.00 & 0.852 & 0.776 & 0.029 \\
\hline Recommended value & $<3$ & $>0.05$ & $0.8-0.9$ & $0.8-0.9$ & $<0.080$ \\
\hline
\end{tabular}

Source: Derived

The above table highlights the CFA or measurement model results. It can be inferred from the above table that the values of various indices of goodness of fit are well within the desired limits. The normed chi-square is 2.385 which are within the desired limit, GFI is 0.852 , NFI is 0.776 and RMSEA is 0.029 . Furthermore, the factor loadings in respect of all the items included in the model exceed 0.5 and are highly significant at five percent level of significance as the $p$ value is 0.00 . Hence, this is considered to be the good model.

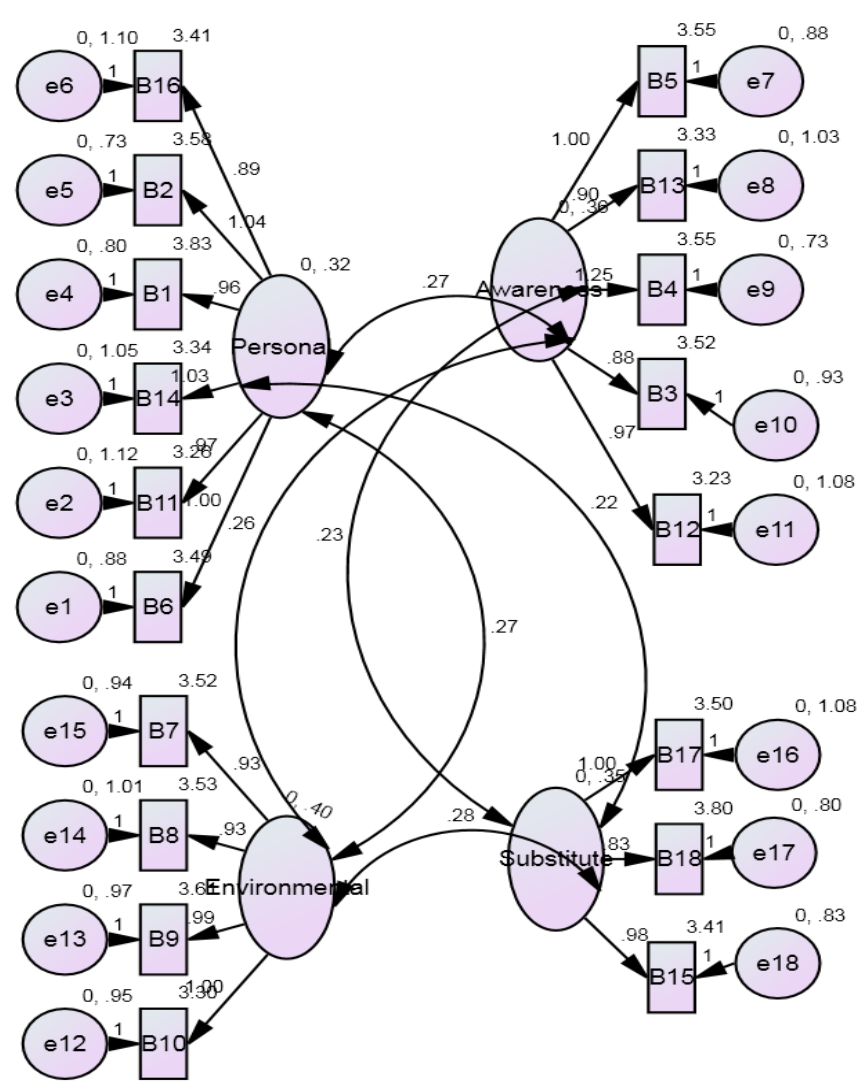




\section{CONCLUSION}

This paper brings to light the steps taken by the Government of Tamilnadu to reduce the usage of plastics and the opinion of the sample respondents regarding the ban of plastics. The study reveals that there is considerable improvement in the steps taken in the reduction of plastics in different zones. The opinion of the sample respondents in respect to the ban of plastics is highly significant in different dimensions such as personal, awareness, environmental and the availability of substitutes. The model framed is fit as per confirmatory factor analysis. Hence it is concluded that wider spread of awareness on environmental protection along with the introduction of proper substitutes for the plastics will wipe away the usage of plastics among the public and thereby the environment will be protected for a better tomorrow. Though recycling is the best option for plastic, methodology and systemization for recycling is slow. While the production model of plastic is very huge and uncontrollable, the numbers of recycling plants are very less.

This vast gap must be closed. According to an international survey, around 600 billion plastic bags are used every year and, because of their in disposable quality, many are swept into rivers or drains not just clogging but eventually ending up in the ocean. This makes plastic bags among the top 10 items of debris found in oceans and coastlines. So, increasing the number of recycling plants in the only option for renewed used on plastic. Besides, plastic ban forces the customer to buy the recyclable plastic bags and reuse of disposable bags. This can also encourage reuse of the bags. Moreover, such a ban could be complemented by ensuring that retail shop keeper and big shopping complexes to team up with plastic recycling firms and set up even collection points for the bags which no longer be reused. Finally, government should educate the public and trade bodies to achieve the benefits of the ban. Since long term benefits of plastic bag ban use will benefit the economy and also save taxpayer money can lead to plastic bag cleanup.

\section{REFERENCES}

1. Abstract - Collected/Seized banned plastics in GCC, Report of Plastic Pollution Free Tamil Nadu Campaign

2. AECOM.2010. "Economic Impact Analysis: Proposed Ban on Plastic Carryout Bags in Los Angeles County", Prepared for Sapphos Enviornmental, Inc. November 32013.

3. Alonso-Magdalena,P.,etal.,The estrogenic effect of bisphenol A disrupts pancreatic beta-cell function in vivo and induces insulin resistance. Environ Health Perspect, 2006. 114 (1): p. 106-12.

4. Ayisha Barveen A and Darling Selvi V (2018), Consumer preference on Green Products, Shanlax International Journal of Management, A Peer-Reviewed, Refereed Scholarly Quarterly Journal, Globally indexed with Impact Factor, Special Issue on Sustainable Green Business (NCSGB 2018) Volume 5, Special Issue 3 March 2018

5. Benachour, N. and A.Aris, Toxic effects of low doses of Bisphenol-A on human placental cells. Toxicol Appl Pharmacol, 2009. 241(3):p. 322-8.

6. Darling Selvi V (2013), Environmental Concern of Indian Paper Industry, International Journal of Management and Development Studies, A Double Blind Peer Reviewed Quarterly Journal, Volume 1, Number 2, July, ISSN: 2321-1423, pp 38-48

7. Jobling, S., etal., A variety of environmentally persistent chemicals, including some phthalate plasticizers, are weakly estrogenic. Environ Health Perspect, 1995.103(6):p. 582-7.
8. National Center for Policy Analysis, http://www.ncpathinktank.org/pdfs/st340.pdf

9. Paigen, B.,etal.,Growth of children living near the hazardous waste site, Love Canal. Hum Biol, 1987.59(3):p.489-508.

10. Thompson,R.C., etal., Plastics, the environment and human health: current consensus and future trends. Philos TransR SocLondB Biol Sci, 2009.364(1526):p.2153-66.

11. http://www.sustainableplastics.org/news/india-issues-rules-plastic-bags-a nd-waste-rejects-full-ban 